\title{
Letter to the Editor: the Divisive Effect of Reductionist Snobbery
}

\author{
WILLIAM A. SILVERMAN
}

90 La Cuesta Drive, Greenbrae, California, USA

The aim of medical science, Sir MacFarlane Burnet wrote some thirty years ago (1), is to provide for all human beings the greatest possible health and length of life and to ensure that the possibility of providing those benefits shall not diminish from generation to generation. He predicted that some stumbling blocks interfering with the achievement of the high aim would become increasingly evident as the number of physicians engaged in medical research rapidly expanded. The development of research and scholarship as a defined professional occupation, he foresaw, would lead to judgments of values, a hierarchy of prestige, and a subtly graded system of rewards. It is hard to deny that there has been a drift in the direction of the predicted hierocracy in medical research. For example, there is a gaping difference in outlook-indeed, a mutual distrust-between those who labor primarily in laboratories and others who spend most of their time at the bedside.

The dualism was made explicit in the widely circulated news report (2) of an address to the Society for Pediatric Research (3): the speaker was reported to have said that nothing instils a healthy skepticism toward clinical laboratory findings like working in a laboratory oneself. Post-doctoral fellows should be required to "participate in research of substance and quality." The emphasis in the news report is revealing of a narrowness of outlook that plagues modern medicine as it struggles to become scientific. The implications are as follows: (1) that physicians must work at a laboratory bench to develop a disciplined scientific outlook and (2) that research of "substance and quality" takes place in a laboratory, not at the bedside. One need go no further than these remarks to understand why so much of preclinical investigation has been of the make-work type and why the quality of clinical studies has been so weak.

The claim that physicians need to leave the wards to develop a healthy skepticism about evidence would be hilariously funny if it was not so dangerously wrong. Instead of exhorting young physicians to develop an interest in the reasoning that forms the basis of the scientific method (4) the speaker was quoted as emphasizing the setting in which investigational activities should take place. A sort of sympathetic magic seems to be involved. Goffman noted, about this general issue (5) that there is an assumption if you go through the motions of science then science will result. Many of the efforts, Goffman continued, remind one of the experiments children perform with chemistry sets: "Follow instructions and you can be a real chemist just like the picture on the box."

The comment concerning substantive research reflects an inflated reverence for the reductionist approach to highly complex problems (the reductionist, when faced with Newton's problem to discover the source of gravity, cuts open the apple and looks inside.) The attitude, moreover, has led to inflationary pressures (too many people chasing too few ideas) and what can only be called the sociopathology of science $e . g$, the shameful inked-skingraft episode in immunology (6) and the bizarre polywater quest in physical chemistry (7). The remarks attributed to the laboratory researcher also revealed a value judgment of the kind noted by Feinstein (8), "The idea that clinical medicine has no intellectual content, with nothing worthy of science, nothing that can be considered a research challenge, is what has kept the state of clinical practice in its current condition of intellectual decrepitude and servitude ..."

The reductionist approach to complexity in medicine is a powerful strategy, but it must not be regarded as the be-all and endall of research. The study of intracellular phenomena and the study of whole body events (singly and in collections) should not be undertaken in isolation from one another. And they must be equally valued and equally disciplined if the wide gap between miracles promised and miracles delivered is to be narrowed in medicine.

One of the most misleading messages broadcast in medical education is the insinuation that narrowness of outlook is "scientific." It is sad to read a report which suggests the myth was supported by remarks before a research society.

\section{REFERENCES AND NOTES}

1. Burnet, M.: The future of medical research. Lancet, 1: 103 (1953).

2. Int. Med. News Service: Expansion of research in pediatrics held essential to ease problems of specialty. Participate in lab research. Ped. News July (1981).

3. Johnston, R. B. Jr.,; The impact of research in pediatrics on the health of children. Pediatr. Res. 15: 1465 (1981).

4. Medawar, P. B.,: Induction and Intuition in Scientific Thought. Am. Philos. Soc., Phildelphia (1969).

5. Goffman, E.: Relations in Public. (Basic Books, New York 1971)

6. Hixson, J. R.: The Patchwork Mouse. (Anchor Press, Garden City 1976).

7. Franks, F.: Polywater. (M.I.T. Press, Cambridge 1981).

8. Feinstein, A. R.: Architecture of clinical research. In: Strategies in Clinical Research, Symposium No. 9, Mead Johnson Co., Evanston (1979). 